\title{
Early Development of Slipped Capital Femoral Epiphysis in a Patient with Infantile Tibia Vara
}

\author{
Hristo Georgiev ${ }^{l}$, Georgi P. Georgiev², Milka Dikova ${ }^{1}$
}

\begin{abstract}
Herein, we present a unique case of an early development slipped capital femoral epiphysis with bilateral infantile tibia vara in a girl of 7 years 5 months of age. There are only few such case reports previously published in the literature. We make a brief review of these pathological conditions involving the physis and compare them to our case. $J$ Clin Exp Invest 2016; 7 (1): 103-105
\end{abstract}

Key words: Slipped capital femoral epiphysis, infantile tibia vara, child

\section{Infantil Tibia Varalı Bir Hastada Erken Gelişen Femur Başı Epifizi Kayması}

\section{ÖZET}

Bu yazıda çift taraflı infantil tibia vara olan ve erken gelişen femur başı epifizi kayması gözlenen 7 yıl 5 aylık bir kız hasta sunulmuştur. Literatürde bu konuda çok az sayıda olgu bildirilmiştir. Yazımızda literatürdeki fizisi de içeren patolojik durumlar kısaca gözden geçirilmiş ve olgumuz ile karşılaştırılmıştır.

Anahtar kelimeler: Femur başı epifizi kayması, infantil tibia vara, çocuk

\section{INTRODUCTION}

Although slipped capital femoral epiphysis (SCFE) and idiopathic tibia vara, or Blount's disease, are considered to have a common etiology and similar histological changes, there are only sporadic case reports of coexistence of these pathological conditions in the current literature. Both diseases include epiphyseal disturbances of lower limbs and are considered to have multifactor etiology [1-6].

Herein, we present an unusual report of a child with an early developed SCFE, after successful treatment for bilateral infantile Blount's disease.

\section{CASE REPORT}

A 4-year-old girl with hypersthenic habitus and weighing $31 \mathrm{~kg}$ was brought to a general practitioner due to progressive varus deformities of lower limbs. She was referred for further examination from pediatric orthopaedic. However, the girl was presented to our department at 5 years 1 months (Figure 1a). The BMI was
23.0, placing the BMI-for-age above the 99th percentile. The pregnancy and birth were normal. Full range of motion in the knee joints on both sides with $10^{\circ}$ pathological knee joint recurvation on the left side was detected (S:0-0-130 right side; S:10-0-130 left side). The left lower limb was $1 \mathrm{~cm}$ shorter than the right. Antero-posterior radiography presented bilateral tibia vara (Figure 1b). Stage IV according to Langenskiold classification on the left side and stage III on the right side was established. The metaphyseal-diaphyseal angle of the tibia was $36^{\circ}$ on the left side and $19^{\circ}$ on the right side. The mechanical tibial/femoral angle was $31^{\circ}$ on the left side and $18^{\circ}$ on the right side. Laboratory tests, metabolic and endocrine markers were in normal limits. Proximal valgus oblique osteotomies were performed on the left side and two months later on the right side. Two years later the child was with normally clinically and radiographically aligned limbs. The metaphyseal-diaphyseal angle of the tibia was $0^{\circ}$ on the left side, and $3^{\circ}$ on the right side. The tibial/femoral angle was $1^{\circ}$ on the left side and $2^{\circ}$

${ }^{1}$ University Hospital of Orthopaedics "Prof. B. Boychev", Medical University Sofia, Bulgaria

${ }^{2}$ Department of Anatomy, Histology and Embryology, Medical University Sofia, Bulgaria

Correspondence: Georgi P. Georgiev,

Department of Anatomy, Histology and Embryology

Medical University Sofia, blvd. Sv. Georgi Sofiisky 1, BG-1431, Sofia, Bulgaria Email: georgievgp@yahoo.com

Received: 04.02.2016, Accepted: 01.03.2016

Copyright @ JCEI / Journal of Clinical and Experimental Investigations 2016, All rights reserved 
on the right side. At 7 years 5 months the child was brought to our institution by her parents due to anterior hip pain on the left side during the previous month. A SCFE on the left side with posterior tilting angle of $15^{\circ}$ was established. (Figure 2a,c) It was accepted as stable according to Loder classification. The Harris hip score was 54 and a positive Drehmann's sign was present. The movements in the hip joint were S: $0^{\circ}$ $10^{\circ}-95^{\circ}$. Full range of motion and normal radiological findings on the right side were established (Figure 2b). At the time of diagnosis the BMI was 27.2, placing the BMI-for-age above the 99th percentile for girls aged 7 years 5 months. Laboratory tests, metabolic and endocrine markers, as well as vitamin D levels (37.3 ng/ $\mathrm{ml}$ ) were in normal ranges. In situ fixation with a cannulated screw of $7.3 \mathrm{~mm}$ was performed. Prophylactic in situ fixation on the contralateral femoral epiphysis was also performed. Postoperative pain relief 30 days later. At 8 months after surgery the child had no pain and Harris hip Score was 95 (Figure 3).
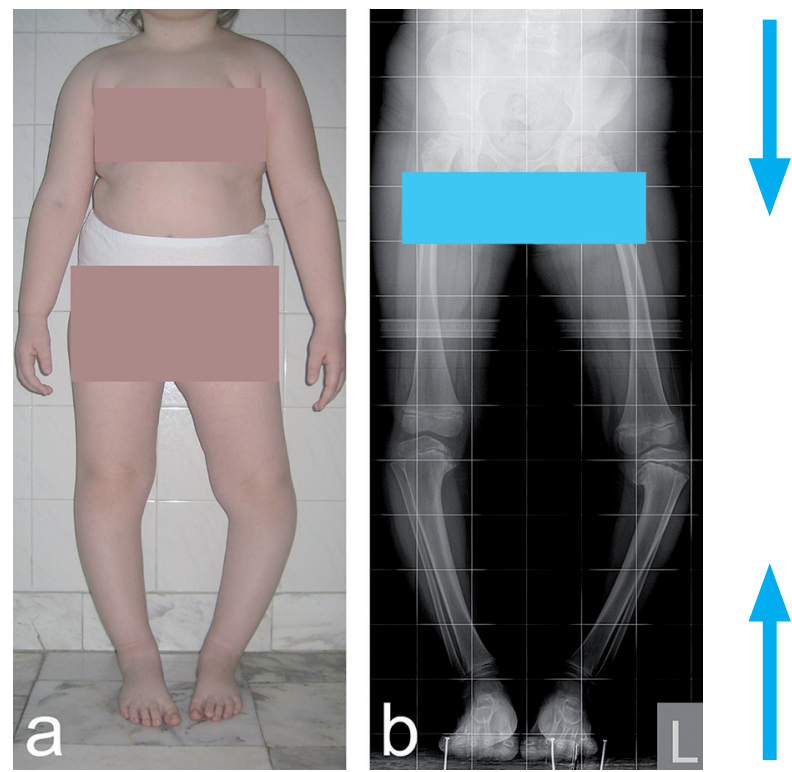

Figure 1. a) Preoperative photograph of the patient; b) Preoperative anteroposterior radiograph
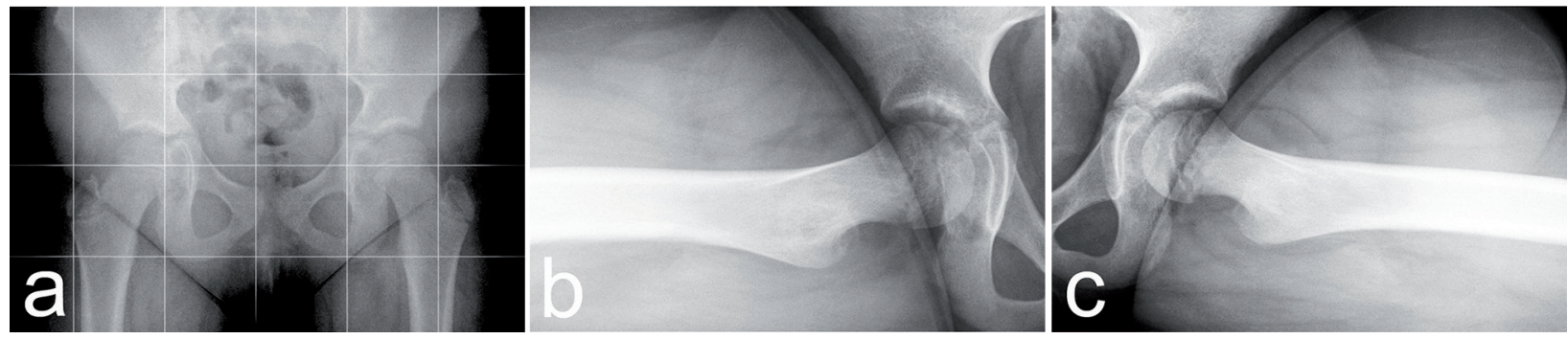

Figure 2. a) Preoperative anteroposterior; b) lateral radiographs (right side) and c (left side)
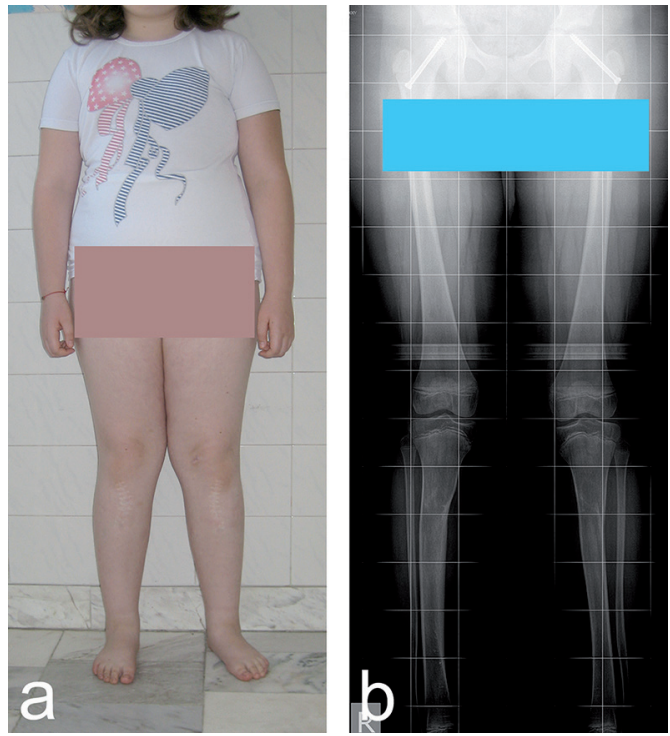

Figure 3. a) Postoperative photograph of the patient; b) Postoperative anteroposterior radiograph after in situ fixation with a cannulated screws

\section{DISCUSSION}

Slipped capital femoral epiphysis is the most common adolescent hip condition, which involves the physis and occurs usually around puberty. It is characterized by postero-inferior displacement of the capital femoral epiphysis on the metaphysis through the physis and affecting patients with an adipose-genital phenotype, endocrine disorders. The presence of mechanical factors, such as excessive body weight or trauma was also involved. Commonly, the average age at diagnosis is 13.5 years in boys and 12.0 years in girls. It should be noted that SCFE has a strong correlation with body weight and the age at diagnosis decreases with increasing obesity $[3,4,6]$.

Tibia vara or Blount disease is another developmental condition, which involves the physis. This pathological condition affects the medial part of the proximal tibial physis and results in deformities of the lower limbs in multiplanar directions. There are two 
forms of Blount disease: early-onset, or infantile, and late-onset. As in SCFE, the etiology of tibia vara is probably multifactorial and includes the mechanical, genetic, humoral, and environmental factors [6,7].

Although SCFE and tibia vara have common risk factors, there are only few reports of coincidence of these two pathological conditions found in the current literature. In 1970, Lovejoy and Lovell reported for the first time two cases of adolescent tibia vara with a concurrent SCFE. In the first case, a 14-year-old boy weighing 77.6 kilograms, with SCFE and tibia vara on the right side was presented. The treatment included in situ pinning on the femoral epiphysis and proximal tibial osteotomy. In the second case, the authors presented an 11-year-old boy weighing 70.3 kilograms with SCFE on the left side and tibia vara on the right side. The treatment included a corrective subtrochanteric osteotomy on the left and proximal tibial osteotomy on the right. In both cases prophylactic in situ pinning on the contralateral femoral epiphysis was also performed. After reviewing a total of 2379 cases operated in their clinic and existing in the literature, Lovejoy and Lovell did not establish true association between tibia vara and SCFE [8]. Schmidt and Mallo [6] presented a case report of an obese black female with infantile tibia vara and slipped capital femoral epiphysis. The authors concluded that the abnormal pressures were involved in the pathogenesis of both diseases [9]. Takikawa and Haga [10] reported a case of an 11-year-old boy with a SCFE following contralateral infantile Blount's disease. The Blount's disease was treated with an orthosis. The authors considered that due to the limb-length discrepancy following tibia vara and the pelvic tilt, the child developed contralateral SCFE [10]. In contrast, Jamil et al. [6] did not find any association between these two conditions. They presented a case of 13-year-old obese boy, with a coincidence of bilateral tibia vara and SCFE on the left side. At 3 years of age an oblique osteotomies of both proximal tibiae were performed as a treatment of tibial deformity; ten years later in-situ screw fixation of upper femoral epiphysis was also performed due to SCFE. This case is similar to ours, however in the present case the SCFE is developed in an early age [6]. This is typical for different endocrinopathies; however in our case metabolic, endocrine markers and vitamin D levels was within the normal ranges and could not explain the extremely rare coincidence of SCFE and tibia vara. Bowen et al. examined three separate groups of obesity-related conditions in adolescent: tibia vara, SCFE and type 2 diabetes; the authors did not find overlap of these diseases at initial presentation and concluded that no association between them could be shown [11]. On the other hand, Madhuri et al. stated that together with high BMI, there is a significant association of vitamin D deficiency and SCFE [12].

Declaration of Conflicting Interests: The authors declare that they have no conflict of interest.

Financial Disclosure: No financial support was received.

\section{REFERENCES}

1. Thompson GH, Carter JR, Smith CW. Late-onset tibia vara: a comparative analysis. J Pediatr Orthop 1984;4:185-194.

2. Weiner D. Pathogenesis of slipped capital femoral epiphysis: current concepts. J Pediatr Orthop B 1996;5:67-73.

3. Aronsson DD, Loder RT, Breur GJ, Weinstein SL. Slipped capital femoral epiphysis: current concepts. J Am Acad Orthop Surg 2006;14:666-679.

4. García-Mata S, Hidalgo-Ovejero A. Valgus slipped capital femoral epiphysis. Iowa Orthop J 2010;30:191-194.

5. Bittersohl B, Hosalkar HS, Zilkens C, Krauspe R. Current concepts in management of slipped capital femoral epiphysis. Hip Int 2015;25:104-114.

6. Jamil K, Abdul Rashid AH, Ibrahim S. Tibia vara and slipped upper femoral epiphysis: is there an association? J Pediatr Orthop B 2015;24:46-49.

7. Sabharwal S. Blount disease. J Bone Joint Surg Am 20091;91:1758-1776.

8. Lovejoy JF Jr, Lovell WW. Adolescent tibia vara associated with slipped capital femoral epiphysis. A report of two cases. J Bone Joint Surg Am 1970;52:361-364.

9. Schmidt TL, Mallo GJ. Slipped capital femoral epiphysis in a patient with infantile tibia vara. Orthopedics 1978;1:471473.

10. Takikawa K, Haga N. Slipped capital femoral epiphysis following contralateral infantile Blount's disease. J Orthop Sci 2002;7:403-404.

11. Bowen JR, Assis M, Sinha K, et al. Associations among slipped capital femoral epiphysis, tibia vara, and type 2 juvenile diabetes. J Pediatr Orthop 2009;29:341-344.

12. Madhuri V, Arora SK, Dutt V. Slipped capital femoral epiphysis associated with vitamin D deficiency: a series of 15 cases. Bone Joint J 2013;95-B:851-854. 